\title{
Los restos de la memoria: sobre la emisión de La Guerra de los Mundos en Quito
}

The remains of memory: on the broadcast of The War of the Worlds in Quito

Os restos de memória: na transmissão de A Guerra dos Mundos em Quito

Iván Fernando RODRIGO-MENDIZÁBAL

Universidad Andina Simón Bolívar - Ecuador

ivan.mendizabal@uasb.edu.ec

Chasqui. Revista Latinoamericana de Comunicación

N. ${ }^{\circ}$ 146, abril-julio 2021 (Sección Tribuna, pp. 15-34)

ISSN 1390-1079 / e-ISSN 1390-924X

Ecuador: CIESPAL

Recibido: 02-04-2021 / Aprobado: 19-04-2021 


\title{
Resumen
}

El artículo analiza la memoria del acontecimiento de la emisión radial de La Guerra de los Mundos por Radio Quito en 1949. Toma como eje la novela de Leonardo Páez, Los que siembran el viento (1982), obra que se debe pensar como un archivo que nos ayuda a comprender los sucesos narrados por el propio creativo-comunicador, el cual además expone el libreto -aparentemente perdido-, por los cuales trata de redimirse del peso sociohistórico que supuso tal emisión. Se examina el libreto incluido en la novela, su narrativa, sus efectos y lo que hace inferir respecto a la vida social y política del momento. Por otro lado, se denota el comportamiento social quiteño y la falta de discernimiento frente a un programa de entretenimiento.

Palabras clave: radiodifusión, radioteatro, literatura ecuatoriana, acontecimiento, memoria social

\begin{abstract}
The article analyzes the memory of the event of the radio broadcast of The War of the Worlds on Radio Quito in 1949. It takes as its axis Leonardo Páez's novel, Los que siembran el viento (1982), a work that should be thought of as an archive that It helps us to understand the events narrated by the creative-communicator himself, who also exposes the libretto -apparently lost-, by which he tries to redeem himself from the socio-historical weight that such broadcast entailed. The libretto included in the novel, its narrative, its effects and what it makes to infer regarding the social and political life of the moment are examined. On the other hand, Quito's social behavior and lack of discernment in front of an entertainment program are denoted.
\end{abstract}

Key words: radio broadcasting, radio drama, ecuadorian literature, event, social memory

\section{Resumo}

O artigo analisa a memória do acontecimento da radiodifusão de A Guerra dos Mundos na Rádio Quito de 1949. Tem como eixo o romance de Leonardo Páez, Los que siembran el viento (1982), obra que deve ser pensada como um arquivo que nos ajuda a compreender os acontecimentos narrados pelo próprio criadorcomunicador, que também expõe o libreto -aparentemente perdido-, pelo qual tenta se redimir do peso sócio-histórico que tal transmissão acarretou. Examina-se o libreto incluído no romance, sua narrativa, seus efeitos e o que faz inferir sobre a vida social e política do momento. Por outro lado, denota-se o comportamento social e a falta de discernimento de Quito diante de um programa de entretenimento.

Palavras-chave: radiodifusão, dramatização radiofônica, literatura equatoriana, evento, memória social. 


\section{Introducción}

El 12 de febrero de 1949 ocurrió un hecho inédito en Quito gracias a la radiodifusión: un programa de entretenimiento provocó incertidumbre y caos en parte de la población. Quienes creyeron su supuesta veracidad ocasionaron la quema del edificio de Radio Quito y Diario El Comercio. El causante fue una obra radial cuyo argumento combinaba la ficción y una simulada realidad, a partir de la adaptación que hiciera en Estados Unidos, Orson Welles en 1939 (2005), de una novela de ciencia ficción de H.G. Wells, La Guerra de los Mundos (1898), que, para el caso ecuatoriano, fue reescrita y realizada por Alfredo Vergara Morales -con el seudónimo de Eduardo Alcaraz- y Leonardo Páez.

La emisión quiteña de La Guerra de los Mundos hoy es parte de la historia de los medios comunicación ecuatorianos, aunque falta analizar sus connotaciones más allá de las anécdotas acopiadas. En este contexto, hay textos que remiten a los hechos, como capítulos y citas en: Fernández (1956), San Félix (1991), Larrea V. (2002), De la Torre (2006), Corral Burbano de Lara et al. (2006), Ribadeneira (2006), Ibarra y Novillo (2010), Guerra Gándara (2008); o ensayos de Gómez (1996), Rodrigo-Mendizábal (2014, 2015, 2021); inclusive menciones en estudios de Schwartz (2015), Beck (2016). Por otro lado, el suceso fue aludido en textos literarios de Égüez (1975) y Alemán (2014).

Sin embargo, hay un asunto objeto del presente artículo y que se refiere al recuerdo del acontecimiento de 1949 por parte del propio protagonista del radioteatro, Leonardo Páez, director del programa y corresponsable de la adaptación. Es esencial saber que este, ya en su autoexilio en Venezuela, escribió la novela Los que siembran el viento (1982), cuyo valor radica en que se constituye en una fuente primaria que puede ser considerada a la par archivo y memoria directa. De este modo, la pregunta que guía este estudio es: ¿Se puede comprender la novela de Páez como la memoria de los restos del radioteatro de 1949 en tanto demuestra -como archivo- tanto los hechos y las acciones que llevaron a la emisión y recepción del radioteatro, cuanto exhibe la existencia del libreto adaptado y, además -como "catarsis"- el testimonio personal del acontecimiento?

\section{Archivo y memoria}

Fundamentándonos en tal pregunta, la noción de archivo es lo inicial para abordar la novela de Páez como objeto comunicativo, Los que siembran el viento, y lo que esta conlleva. Tal noción, desde ya, se aparta de su sentido consabido: como centro o depósito de documentos, y más bien se relaciona con lo que apunta Foucault: "el juego de las reglas que determinan en una cultura la aparición y la desaparición de los enunciados, su persistencia y su borradura, su existencia paradójica de acontecimientos y de cosas (2013, p. 238). Ingresar al archivo es denotar la red que contiene, los conceptos que permite 
desarrollar, la ley primaria que estipula su emergencia donde el lenguaje es la herramienta primordial. Como emplazamiento de partida, permitiría formar el conocimiento contenido en un tipo de discurso. Sabemos que aquella palabra tiene su raíz en la voz arkhe que alude a inicio, origen o principio, pero que, de acuerdo con González Echevarría, su sentido también se lo debe considerar en tanto esfera donde se origina y reside la Ley, su poder y su secreto: es allá donde se le guarda y está codificado (2011, p. 61). El arkhe tendría que ver con lo que origina y con lo que en él está contenido como principio de las ideas. Es desde allí que hallamos el sentido de las cosas, al mismo tiempo que es un emplazamiento a cuyo orden nos sujetamos y tratamos de inquirir los secretos que denotan la realidad referenciados. Juzgándolo así, el archivo conlleva al "proceso mediante el cual se escriben textos; [es decir,] un proceso de combinaciones repetidas, de mezclas y entremezclas regidas por la heterogeneidad y la diferencia" (p. 53). Los enunciados, los razonamientos, las ideas, el saber, gracias a las posibles combinaciones formarían hechos discursivos que delimitan a la cultura productora. Acudir al archivo es para ir a los discursos o hechos de discurso. Con Foucault apuntaremos entonces que:

Analizar [tales] hechos discursivos en el elemento general del archivo es considerarlos no como documentos -de una significación oculta o de una regla de construcción-, sino como monumentos; es -al margen de toda metáfora geológica, sin atribución alguna de origen, sin el más menor gesto hacia del comienzo de una arkhe- hacer lo que podríamos llamar, según los derechos lúdicos de la etimología, algo así como una arqueología (2013, pp. 238-239).

La novela es parte del archivo como hecho discursivo, el cual abarca procesos y situaciones expresados como enunciados que conforman un discurso sobre una realidad. Los que siembran el viento, así, es un discurso literario acerca de la realidad ecuatoriana de su momento, así como un hecho de discurso de Leonardo Páez motivado por aclarar una situación sociohistórica y mediática que tuvo efectos en su vida personal y en la memoria de los quiteños. Visto así, sería un monumento donde habría trazos de procesos, cuyas combinaciones y citas deben ser examinadas. Con Echevarría precisaremos que: "Como el Archivo, [tal] novela atesora saber. Como el del Archivo, ese saber es del origen, es decir, del vínculo de su propia escritura con el poder que lo hace posible, por consiguiente, con la posibilidad misma de conocimiento" (2011, p. 62). Inquirir a dicho saber es indagar el origen implícito en la novela y, con ello, cierto poder latente en su seno: puesto que el interés es lo discursivo, iremos al acontecimiento interpretado, el libreto radial que contiene y, con ellos, saber que estos asuntos trascienden la anécdota.

Dicho lo anterior, otro asunto de este estudio es la memoria. Agamben ha apuntado, con referencia al sobreviviente de un acontecimiento -para su caso era el campo de concentración y la Segunda Guerra Mundial-, que aquel tiene "la vocación de la memoria: no puede no recordar" (2000, p. 26). Un sobreviviente 
es aquel que habría escapado del horror y erigido en testigo. Esta palabra en griego, según Agamben, es martys o mártir, cuya raíz indoeuropea mer tiene que ver con "recordar", por lo que la memoria estaría conectada con el recuerdo, además que entrañaría al acto de testimoniar. Habría unos conceptos conexos necesarios por destacar: el de acontecimiento, el de testimonio y, sobre todo, esa aserción compleja: "no se puede no recordar". La memoria abonada en el archivo impide que no se pueda no recordar.

Bergson postula que "toda percepción es ya memoria" (2006, p. 172). Lo que forma la memoria es la impresión de la realidad o la percepción de elementos de los cuales solo se recuerdan los que han tenido más efecto. La función de la memoria, así, sería la de "evocar todas las percepciones pasadas análogas a una percepción presente, recordarnos lo que ha precedido y lo que ha seguido, [y] sugerirnos [...] la decisión más útil” (p. 248). Bergson discurre sobre la percepción de la realidad cuyas imágenes configuran la memoria por la cual recordaríamos el pasado, mirando lo que este ha dejado como huella en el Ser.

Pero sus postulados no son ajenos a lo que se intenta discutir, en sentido que, si el novelista Páez, no puede no dejar de recordar lo vivido en 1949, es porque de ese año habría una memoria personal compuesta por una serie de impresiones que, sin duda, las quiso ordenar en su novela en función del archivo propio y también social; por otro lado, dado su autoexilio en 1955 (X. Páez, 2010, p. 91; Wyss, 2014, párr. 24), consecuencia de la emisión radial, se debe pensar que Los que siembran el viento presenta una explicación inequívoca aprovechando la lejanía del tiempo y del lugar del acontecimiento, Quito, en el entendido que la novela en mención fue escrita y publicada en Caracas-Venezuela en 1982. En tal novela lo que está presente no es el pasado, sino el acontecimiento suscitado: la transmisión de una radionovela que creó en la población una realidad con sus propias determinaciones. Pero, además, otros detalles que las crónicas o la historia de los medios de comunicación ecuatorianos no necesariamente lo explicitan.

Se puede decir entonces que mediante la memoria se va al acontecimiento. Bergson dice que "todo acontecimiento cuyo recuerdo se ha impreso en la memoria, por más simple que se lo suponga, ha ocupado un cierto tiempo" (2006, p. 193). Si Los que siembran el viento fue escrita y publicada en 1982, reconocemos allá lo que ha turbado la memoria de Páez, reflejándole en datos de un tiempo más extenso, sintetizados en la memoria novelesca con su propio tiempo-espacio y su mundo posible en el que "hay una manera de ser o [...] un estado de cosas posible de algún tipo" (A. Plantinga cit. en Pavel, 1995, p. 67). Entenderemos, en todo caso, la noción de acontecimiento tal como postula Deleuze, como un "devenir-ilimitado, [...] con todos los trastrocamientos que le son propios, del futuro y el pasado, de lo activo y lo pasivo, de la causa y el efecto. [Es] lo que acaba de pasar y lo que va a pasar, pero nunca lo que pasa" (2005, p. 34). El acontecimiento es lo de ese 12 de febrero de 1949 y que en el momento de su ocurrencia ya implicaba un devenir: la emisión de una ficción que hizo 
que la gente creyese firmemente que había una invasión marciana en ciernes, llevándole al desconcierto, al incendio de Radio Quito, con el resultado de seis muertos (Ribadeneira, 2006, p. 142), varios contusos, además de diligencias relacionadas con la justicia, hasta el autoexilio de Páez a Venezuela. En otras palabras, aconteció y suscitó acciones, y aunque haya incitado una memoria colectiva y personal, tal acontecimiento se hizo coextensivo al lenguaje (Deleuze, 2005, p. 35), provocando, si bien textos noticiosos u otros, principalmente el que lo sintetizó: la novela autorreferencial de Páez con la que pretende redimirse.

Ahora bien, cabe preguntarse, dado el acontecimiento enunciado, cuánto de lo recordado pertenece a la realidad y cuánto a la imaginación productora que, para Bachelard, tomando en cuenta a Bergson, implica una voluntad donde las imágenes recordadas del acontecimiento supondrían ciertas libertades que el espíritu se tomaría con respecto a la naturaleza o la realidad (2016, p. 20), hecho que suscita el discurso poético que, para nuestro caso, será el discurso literario de la novela. En este contexto, Bergson nos dice que el pasado, cuando es activado por la realidad recordada, es tal porque está "imaginado por el espíritu" (2006, p. 245). Entonces digamos que Páez cuando escribió Los que siembran el viento, más allá del archivo de la memoria, el recuerdo le llevó también a ir a su espíritu poético, para no elaborar un puro texto explicativo como un ensayo o un informe, sino una novela en la que "la memoria [se abordaría] verdaderamente en el dominio del espíritu" (p. 262). El espíritu, con el paso de los años, obliga a Páez a "no poder no recordar" y la novela vendría a ser su testimonio.

\section{Leonardo Páez y su trascendencia en la cultura ecuatoriana y venezolana}

Hay un hado que prescribe la obra de Leonardo Páez (Quito, 1912 - Mérida, 1991). Antes que radialista, era hombre de teatro. Vacas cuando lo conoció, lo describe como un actor, con su "exageración en el hablar y en el gesto" (1975, pp. 6-7). Escribió teatro en la década de 1930 presentándose, "con supuestos nombres de autores extranjeros inventados para atraer al público" (p. 6). Así mismo, publicó poesía, siendo su primer libro, Romancero quiteño (1939), influido, según Vacas, por Federico García Lorca. El hado referenciado tiene que ver con su actitud hacia el escenario, con cierto histrionismo y fingimiento teatral. Llama la atención, por otro lado, que en las obras teatrales usaba seudónimos: una hipótesis es que la autoría foránea era mejor garantía ante lo nacional; en este marco, Vacas nos hace inferir que en su momento prevalecía el desprecio cultural a la literatura y al arte producidos en Ecuador.

Pese a lo dicho, en 1955, Páez recibió el 2do. Premio del concurso de la Sociedad Amigos del Teatro por su obra La bruma frente al espejo -publicada en 1957 en volumen doble junto a Lluvia de verano por la Casa de la Cultura Ecuatoriana-. Al recibir el premio, Páez señaló: 
que la obra premiada es el fruto de años y años de transitar por los senderos de los escritores, casi siempre sembrados de guijarros, tanto más dolorosos cuanto que el hombre de teatro tiene que internarse en ese bosque caprichoso y temido que es el público, al que algunas veces hay que darle gusto y esperar el momento de asestarle el golpe de efecto preciso y certero, muchas veces cediendo a sus caprichos" (cit. en M. de Uzcátegui, 1955, p. 156).

Páez reconoce que hacer teatro en Ecuador es problemático, peor cuando el público no es receptivo, para lo cual debe emplearse estrategias creativas para seducirlo, además que la labor teatral no tiene el reconocimiento cultural como se esperaría. Si en 1939 se adoptaba nombres extranjeros apócrifos, en 1955, se seguía bregando en medio de un público indiferente, acaso hostil, desafiando sus caprichos. ¿No hay acá quizás ciertos rastros que permiten entender cómo se receptó la radionovela en 1949 ?

Páez, además de poeta y dramaturgo, fue periodista y músico popular. Ribadeneira es efusivo al describirlo, señalándolo con el apodo con el que se le conocía, “el 'loco’ Páez”:

un quiteño total [...]. Compositor, cantante, poeta, recitador, jefe de pesquisas, galán joven, director teatral, periodista, locutor. $\mathrm{Y}$, sobre todo, el rey del radioteatro criollo, en una época de competencia entre las emisoras que tomaron fuerza en Quito en los años cuarenta, luego de que hicieron acto de presencia en el Ecuador desde 1929 (2006, p. 142).

Páez se educó en el Colegio Mejía, aunque su vida profesional fue la de un autodidacta. Como músico "componía con gran facilidad música popular ecuatoriana, pintando costumbres del viejo Quito, [...incluso, regalando y vendiendo] sus derechos de autor" (X. Páez, 2010, p. 92). Igualmente probó el canto, formando un "dúo con Luis Villavicencio, [y luego integrar] la Orquesta Típica de Música Argentina [con la que grabó un disco] para la RCA Víctor" (Correa B., 2014, párr. 1). Como compositor es reconocido por sus pasacalles, albazos, cachullapis, pasillos, etc., los que llegan a sumar unas 60 composiciones solo compuestas en Ecuador (X. Páez, 2010, pp. 142-143), entre ellas: "La naranja", "Reina y Señora", "San Francisco de Quito", "Romance de la naranja”, "La tuna quiteña", "El panecillo", "El Chacarero", "Peshte longuita”, etc. Para Ribadeneira, “La tuna quiteña' fue durante varias décadas una canción muy popular, infaltable en las farras, especialmente a la hora del 'saltashpa', según se relata” (2006, p. 142). En forma póstuma el Concejo Metropolitano de Quito -cuando se celebraba el CDLXV Aniversario de la Fundación de Quito- le otorgó la Condecoración posmortem por Gran Exponente de la Música Nacional Ecuatoriana en 1999.

Su labor teatral, poética y musical la siguió desempeñando en Mérida, Venezuela, tras su autoexilio, donde además cultivó el dibujo y la pintura. Su hija afirma así: "las ilustraciones de sus publicaciones casi todas eran dibujos 
y pinturas suyas" (L. Páez, 1982, p. 93). La tapa de Los que siembran el viento vendría a ser un diseño suyo.

Imagen 1. Diseño de tapa deli libro Los que siembra el viento

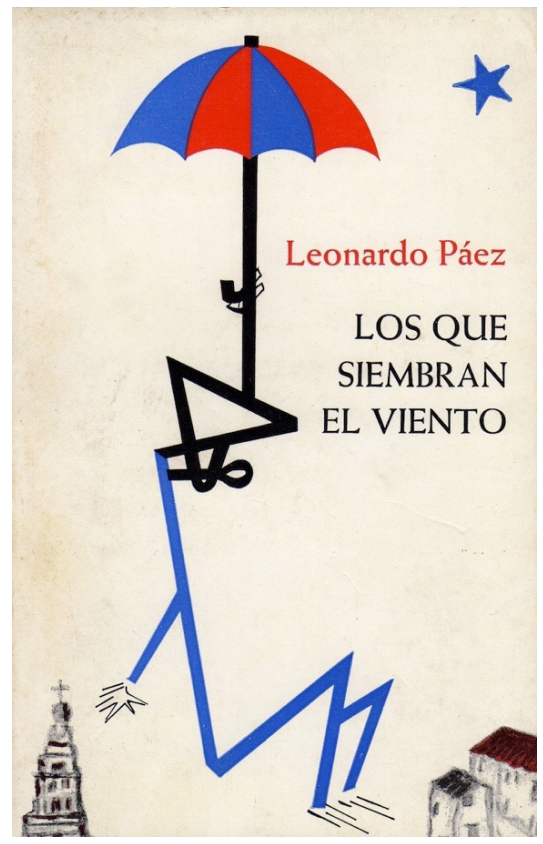

En elámbito de la radiodifusión, trabajó en Radio El Prado (Riobamba) y HCJB (Quito), luego como director artístico de Radio Quito. En Mérida (Venezuela) fue director de la Radio de la Universidad de Mérida. Por sus labores recibió el Premio Emilio Menotti Spósito, además de la Orden Don Tulio Febres Cordero en primera clase, otorgado por la Asamblea Legislativa Estado de Mérida en 1989, y la Orden Francisco de Miranda (X. Páez, 2010, p. 166).

Sobre el libretista que trajo la versión de La guerra de los mundos a Ecuador, Alfredo Vergara Morales (Santiago de Chile, 1915-México, 1987) cuyo pseudónimo era Eduardo Alcaraz, señalemos que este trabajó con Páez en la adaptación y la puesta en escena de tal obra en Radio Quito en 1949. Era un hombre dedicado al teatro; había logrado conseguir el libreto de Orson Welles y lo propuso a Radio Quito según uno de los actores del radioteatro, Oscar Guerra (cit. en Guerra Gándara, 2008, p. 117; además, Ribadeneira, 2006, p. 143). Mientras estuvo en Quito, trabajó en radioteatro hasta que en 1951 se fue a México. Ribadeneira, recuerda a Vergara Morales como el “'roto' trotamundos. [... Y] como buen trotamundos, estaba dispuesto a todo. [Es así como] el chileno Alcaraz -según consta en publicaciones de El Comercio- dirigió una escuela de radioteatro, fue 
director de obras teatrales en alguna emisora, canto y bailó tangos y sambas" (pp. 143-144). San Félix reafirma que el chileno llegó como cantante de tangos, luego dictó ciertos cursos de producción radial, fonética y actuación, pronto dirigió teatro, hasta insertarse en el radioteatro; incluso indica que terminó una novela con el título de La Madrastra (1991, p. 63). En todo caso, se observa que la carrera artística de Vergara Morales despuntó en México, en el mundo del cine y la televisión.

\section{La Guerra de los Mundos, contexto y radioteatro}

Entre julio de 1941 y enero de 1942 Ecuador libró una guerra con Perú, incitada por este país, aprovechando un problema de fronteras no resuelto sobre una región de la Amazonía, pese a que se había firmado el Tratado Herrera-García de 1890 en el que Perú reconocía "el derecho al condominio amazónico" (Pareja Diezcanseco, 1979, pp. 387-388). Desde 1935, este país estaba fraguando una invasión que, en efecto, se dio el 5 de julio, cuando el mundo estaba en tensión con la Segunda Guerra Mundial, la amenaza nazi-fascista y ciertos países latinoamericanos, entre ellos Perú, según Pareja Diezcanseco, pretendían apoyar las tesis de Hitler y hacer desaparecer Ecuador del mapa (p. 391). ¿Cuáles eran los intereses, aparte de los expansionistas? El caucho y la presunción de la existencia de petróleo; esto intensificaría más la economía de Perú y la región. El caso es que la invasión se realizó con desventaja para Ecuador, porque no había advertido que Perú ya había construido infraestructura en la Amazonía y desplazado personal militar; Ecuador, por el contrario, tenía pocos efectivos militares y pertrechos. El Tratado de Río de Janeiro en 1942 dio fin al conflicto con la pérdida territorial de la Amazonía para Ecuador. En este contexto, el gobierno de Carlos Alberto Arroyo del Río "hubo de soportar una responsabilidad trágica, y terminar tres años más de gobierno en un país empobrecido, desmoralizado y extenuado por la derrota" (p. 387).

La memoria de la guerra con Perú y la derrota pervivió en los siguientes años motivando descontento contra el gobierno hasta que se dio la revolución de la Gloriosa en 1944 y la desestabilización del Estado hasta la llegada al poder de Galo Plaza Lasso. Este propició una transformación socioeconómica gracias a la exportación del banano, además que en su gestión "supo escuchar el mensaje íntimo de la conciencia nacional: crear la atmósfera de paz y estabilidad que el Ecuador [requería] para desarrollar sus recursos" (Pareja Diezcanseco, 1979, p. 407). En ese ambiente de paz que aplacaría la conciencia nacional dolida es que el programa de radio de Páez-Alcázar se produjo, tocando, quizá, finamente, los nervios aún convalecientes de quiteños o ecuatorianos.

Presentar en este ambiente un radioteatro sobre la invasión marciana no tuvo nada de deliberado, pero si juzgamos el espíritu de la época, cobra cierto sentido el acontecimiento en tanto una parte de la gente quiteña creyó la ocurrencia de otra invasión real. La ficción de los marcianos, por otro lado, 
resultó no meditada en el momento de su recepción, quizá porque, aunque mucha gente creía la existencia de seres extraterrestres, en su tiempo muchos fabulaban cosas fantasiosas sobre ellos, pese a la existencia y el conocimiento ya del libro de Wells (E. Uzcátegui, 1985, p. 8), siendo no necesariamente tales fantasías ligadas a una supuesta invasión, si se la entiende a esta como irrupción violenta.

Si se piensa que La Guerra de los Mundos, versión ecuatoriana, era uno más de los radioteatros que presentaba Radio Quito, y recogiendo más bien el tono festivo que prevalecía en Quito, la ciudadanía pasó por alto la naturaleza del entretenimiento en ciernes, siendo confundidos por lo "realista" de la presentación del programa, el cual tenía el formato de un programa musical que pronto era interrumpido por revelaciones noticiosas. Esto ya estaba presente en el trabajo de Orson Welles, pero para la población quiteña tal formato fue un hecho nuevo: no existió conciencia de que las intermitencias noticiosas eran pura ficción. De este modo, habría un contraste entre la actitud receptiva de las audiencias frente a un formato que palpablemente pudo confundir, gracias a que se pasaba de una transmisión pactada de un concierto real de pasillos, del dúo Benítez y Valencia, a la narración de la invasión como tal. La novela, en este contexto, presenta el libreto en forma de relato y lo contrapone con las actitudes y el desconcierto de la población quiteña que fue atrapada por el relato. Cabe decir, en este punto, que por muchos años se pensó que el libreto de La Guerra de los Mundos había desaparecido por efecto del incendio de Radio Quito y El Comercio; Páez hace un esfuerzo de memoria y recupera, si bien no el libreto total, al menos una parte, siendo este además un aporte invaluable de su novela para los estudios de comunicación. Comprendemos así que estamos ante un archivo que entreteje una serie de circunstancias no solo ficticias sino también del contexto real del momento. Analizamos a continuación algunos detalles del libreto y sus imbricaciones sociocomunicacionales.

\section{a) Irrumpiendo la noche quiteña}

Cabe decir que la transmisión del radioteatro había sido avisada, según Páez, con anticipación entre las páginas de El Comercio y Últimas Noticias (1982, p. 26). Pese a tal indicación, los radioyentes no adivinaron la naturaleza del programa. Este comenzó como uno de más del entretenimiento nocturno del sábado, en el que habría música nacional, a cargo del Benítez y Valencia, los cuales, según la novela, alcanzaron a tocar el pasillo "Para mi recuerdo". Pronto fueron interrumpidos por un locutor para anunciar la invasión marciana: “[...] la civilización está herida de muerte. Es el hombre en su tragedia. Es la especiefrente a su desaparición... ¡Por irremediable, señores, aceptemos los irremediable!” (p. 15). Nótese el tono apocalíptico de la elocución, el anuncio de un terrible final para la humanidad. Esto se refuerza con el pedido: "Demostremos de lo que es capaz el hombre. En estos supremos instantes de prueba, juntémonos y 
confortémonos mutuamente. Distribuyámonos con equidad este castigo que nos cae del cielo" (p. 16). El programa hurgaba el sentimiento terrorífico religioso, insinuando que se escuchará como verdad, la crónica del castigo desde el cielo.

Y lo curioso: el fin del mundo estaba patrocinado por una bebida nacional; así, el locutor dice: "Importante: los boletines informativos que están escuchando, señoras y señores, tienen el patrocinio exclusivo de Orangine, el insuperable refresco de naranja" (L. Páez, 1982, p. 16). La repetición publicitaria de tal bebida se da entre las noticias de la invasión. Pese a eso, la audiencia reparó tarde que todo era un programa ficticio que, sí, tenía un tinte apocalíptico.

\section{b) Informando la invasión}

Tras la suspensión abrupta del recital, el locutor resalta que el programa será informativo y, como tal, empieza avisando el avance de los minutos. La primera irrupción inquietante-apocalíptica, en efecto, se dice a las 9:06 de la noche. A las 9:21 la transmisión no solo ha captado la atención, sino que ha provocado una serie de problemas entre personas, en el seno de ciertas familias, ha sembrado desconcierto y provocado la ira de la población. Para cuando inicia la quema del edificio de Radio Quito y El Comercio, según la novela, apenas habían transcurrido 17 minutos narrando hechos terribles; al cabo de esos minutos se dice metafóricamente que se ha detenido el reloj (L. Páez, 1982, p. 52).

¿Y cómo se hizo para detener el reloj de la atención ciudadana? A las 9:06 otro locutor -al parecer eran dos los relatores-ingresa y avisa que se presentará el jefe de información de El Comercio. Un ambiente tenso en el que hay ruido de acordes musicales y de pasos, lleva a que justamente tome el micrófono el ficticio jefe. Este señala que la invasión se ha consumado y que los marcianos avanzan a Quito desde Cotocollao:

Hay información que denuncia la presencia de los marcianos en las inmediaciones de El Cinto, en lo alto de Lloa. Si los datos son verídicos no queda sino entender que el mortal enemigo nos tiene cercados. Un paso más, Chillogallo, luego La Magdalena y Quito. De lo que acontezca en otros países nada es posible señalar. Las agencias internacionales de noticias han suspendido sus transmisiones. Ignoramos, así mismo, detalles sobre la suerte que han corrido nuestros reporteros destacados en Cotocollao. Se desconoce si nuestro ejército ha entrado en contacto con el enemigo. Es todo cuanto se sabe en el diario El Comercio (L. Páez, 1982, pp. 24-25).

Adviértase la figuración militar esbozada respecto a la invasión, sobre un ejército que desciende de las supuestas naves marcianas y toma poblaciones antes alejadas de Quito. Y más adelante, cuando se desea que no "caigamos, definitivamente, abatidos por el insospechado poderío bélico del gigantesco usurpador espacial" (L. Páez, 1982, pp. 25-26), percibimos que el lenguaje del enunciador referencia a un "usurpador" que tiene un impensado poderío bélico. 
Parece que los libretistas trastocan acá el imaginario de la invasión peruana, y más aún el de la Segunda Guerra Mundial, prevalecientes aún.

¿Y quiénes informan? Son los "valientes periodistas" (L. Páez, 1982, p. 35). Pero de ellos aún no se sabe, según se enuncia en el programa. Pues virtualmente están en el lugar donde los marcianos han ocupado. El locutor desesperadamente clama que al menos algún periodista se comunique. Luego de otros incidentes ciudadanos relatados en la novela -como un correlato de la emisión-, recién será a las 9:20 que se consigue la conexión con un periodista que está en la Plaza central de Cotocollao, el cual dice:

A escasos cien metros de este lugar se distinguen dos extrañas formas. Dos estructuras semejantes a esas torres metálicas [...]. Si tales artefactos medio grises son los invasores, ¿qué podría hacerse para destruirlos? [...] ¡Atención, atención!... ¡Un marciano se ha movido!... ¿Marciano?... ¡Sí, si, esa cosa tiende a... no es fácil expresar lo que se está viendo!... ¡Pareciera desplazarse lentamente, tanto hacia la izquierda como hacia la derecha, de manera algo similar a la danza clásica!... ¡Oh, qué espectáculo! [...] El frío ha desaparecido. Del cerro viene el gañido de un perro. ¿Dónde ha quedado el aire? De lo alto de uno de los esqueletos metálicos -deben de ser metálicos- ha salido un largo brazo y de lo que valdría la pena calificar de mano, surge algo tal vez acuoso como disco transparente que gira hacia la izquierda. Dispara un chorro líquido ambarino. [...] El torrente de luz viene hacia mí y yo lo espero... ¿Qué me ocurre?... [...] ¿Qué ha sido de mí?... ¡Ahhhh! (L. Páez, 1982, pp. 45-48).

A ratos la narración se presiente falsa y hasta contradictoria. Si antes se aludía a un poderoso aparato militar que avanzaba sobre poblaciones, la narración del periodista frente a lo que ve es otra cosa: una nave que asemeja una torre; unos marcianos que son una especie de cangrejos; un brazo desde la nave que enfoca a la víctima y le dispara. Frente a la narración apocalíptica que previamente se menciona, en esta parte del programa se insinúa a unos marcianos que danzan, que ejecutan un ritual y matan. Se pasa por breves minutos a lo fantástico, suspendiendo el terror por el espectáculo de la incertidumbre. ¿Un ritual para matar? ¿Y cómo es eso de la invasión de poblaciones al modo de un ejército organizado? Con todo, la transmisión de lo que se informa se corta abruptamente con la muerte del periodista. Segundos después el locutor de Radio Quito anuncia entre gritos de desesperación al aire: “¡El más destacado cronista de sucesos ha sido desintegrado!... Leonardo Páez ha muerto” (L. Páez, 1982 , p. 48). Nótese que el propio director y libretista figuradamente muere; Páez se auto-representa como un periodista o un cronista de sucesos. Llegado a este clímax, el programa se suspende y el acontecimiento se ha impuesto con notables consecuencias. 


\section{c) La representación de la autoridad}

Y volvamos antes del clímax. A las 9:16 se anuncia el discurso del ministro de gobierno en nombre del presidente de Ecuador, además del ministro de defensa. Es otro actor-locutor el que imita a la autoridad. Lo sustancial de su mensaje radica en que hay un tono patriotero -"Compatriotas, me es doloroso dirigirme a Uds., en esta situación realmente crítica” (L. Páez, 1982, p. 36)-, a sabiendas de una supuesta derrota. Y se dirige a la nación señalando que se resistirá, "hasta el sacrificio mismo" (p. 36); aunque reconoce que "nuestras armas no poseen las características mecánicas [...] indispensables para contrarrestar a las del colosal enemigo" (p. 37). Si es que en el programa se fabula con la invasión marciana, es probable que tales palabras, considerando el contexto de posguerra, en efecto hayan calado el imaginario de mucha gente que creyó en una nueva invasión real de algún enemigo cercano. Y adviértase que, a la par, el locutor enfatiza algo curioso:

Me atrevería a imaginar que, a pesar de la emergencia, algo se sacará en limpio, pues se nos brinda la oportunidad de un balance [...]. Mi memoria es sensible al recuerdo de aquellas horas negras cuando nuestros proyectiles sirvieron mucho menos que nada, pues no encajaban en los fusiles o no salían de estos, como tiene que ser y es de costumbre, para ir al lugar de su destino, disparados, una vez, con la mejor puntería de este mundo. ¿Traición, traición? ¿Quién sabe!... Quizá imprevisión y desidia (L. Páez, 1982, pp. 37-38).

¿Es esta una lectura al sesgo de lo pudo llevar al fracaso bélico cuando se dio la invasión peruana? Encarnar la autoridad estatal afirmando tales palabras supone cierta actitud de reproche sobre los acontecimientos históricos, si se piensa que la opinión pública de ese momento era crítica frente a los gobernantes y políticos que ocasionaron la desprotección de la Amazonía como territorio patrio, entre otros asuntos (Orquera Polanco, 2020, p. 66).

\section{Novela testimonial y catarsis}

Ximena Páez, cuando reseña la obra de su padre, apunta: "Sobre [los] sucesos de [1949], escribe casi cuarenta años después una novela: Los que siembran el viento, donde relata y aclara muchos rumores inciertos en relación con esta representación teatral y su repercusión en la ciudad" (2010, pp. 91-92). Esta aseveración es clara y cierta. La obra mencionada es marcadamente testimonial y catártica. Páez es el centro de la historia, aunque el narrador tome distancia en el relato y lo presente como el personaje Páez. Por ejemplo, leemos casi al inicio, cuando le describe y alude a El Comercio y Radio Quito:

El hombre de quien se ha venido hablando trabaja en dicho diario, así como en su estación de radio que queda en el tercer piso. Resulta curioso enterarse de lo 
que, más o menos, se le achaca: que conversa consigo mismo, como loco; que en el trayecto del va y viene suelta palabras sin pies ni cabeza (L. Páez, 1982, p. 9).

Cuando principia la novela el personaje es alguien con pocos recursos, que vive en un cuarto arrendado en el centro de la ciudad, dedicado al teatro, a componer música y a hacer labores en la radio. Tal hombre de quien se habla en el párrafo citado es Páez. Y quien lo refiere es un narrador omnisciente, el propio escritor Leonardo Páez. Esta voz entremezclada, entraña lo testimonial, es decir, "no poder no recordar", en los términos de Agamben: conjura la memoria de los hechos y se libera de una carga sociohistórica.

Su novela tiene que ver con el subgénero de lo documental, el cual, para Álamo Felices -citando a los hnos. Edmond y Jules de Goncourt-, implica a la novela testimonial, la literatura factográfica, la novela-realidad o la cronovela, en las que habría una "honda concepción mimética" (2011, p. 56). La intención en este tipo de literatura es ceñirse a los hechos, haciendo una relación cronológica de lo acontecido, similar a la crónica literaria que, en el caso de Páez, incluso tiene humor, color local y suspenso. Allí pone uno que otro verso de su creación musical. Lo mimético estaría en reflejar la realidad y, con ello, ser lo más verosímil posible. Por ejemplo, mediante la narración, el autor cuenta:

La corpulenta campana de la Virgen de la Merced coincide con los relojes de la emisora y da las nueve. Dos soplos de clarines que se levantan dificultosamente de un disco rayado anuncian el programa súper-extraordinario. Luego de arrojar al suelo el pucho de cigarrillo que bailaba entre los labios, y aniquilarlo en el piso, el locutor Raúl López camina hacia el micrófono. Crea un suspenso de dos segundos, se engatilla y resueltamente se lanza: “¡Buenas noches queridos amigos del aire! ¡Son las nueve en el territorio nacional!... ¡El fabuloso programa de la canción criolla, el esperado certamen radial del sentimiento, con la participación de sus más calificados intérpretes de todas partes va a iniciarse!... ¡Tendremos hoy, estimados radioescuchas, óiganlo bien, y recuérdenlo, una noche verdaderamente inolvidable, inolvidable, dable, dable, ble, ble, ble!" (L. Páez, 1982, pp. 12-13).

Minutos previos a la emisión radial se describe el momento, la atmósfera nocturna y se introduce al locutor anónimo. Reiteremos que desde el inicio Páez señala que habría habido el anuncio del programa cuya característica era ser "súper-extraordinario" y, además que devendrá en "inolvidable"; además, su singularidad, aunque no necesariamente que el contenido trataba de alguna invasión marciana.

Considerando lo señalado, con Beverley anotemos que Páez hace una especie de non-fiction novel (1987, p. 9), novela testimonial, donde deja claro que su personaje es un ser humano como cualquier otro, dedicado, esto sí, al teatro y a la radiofonía; que contará con detalle los hechos durante la transmisión del programa y los posteriores sucesos, jugando "entre lo literario y lo no literario, [...cuya] unidad narrativa [es] una vivencia particularmente significativa, [en 
la que] la situación del narrador en el testimonio siempre involucra cierta urgencia o necesidad de comunicación que surge de una experiencia vivencial" (p. 9). Desde ya deslindemos algunos de los rasgos de la novela documental o testimonial y resaltemos otros pensando en Los que siembran el viento:

- Que no es autobiográfica en sentido estricto -aunque el subgénero comentado lo contiene-;

- No está narrada en primera persona;

- Tampoco es etnográfica ya que no es una indagación de los hábitos de los implicados en el radioteatro, aunque se rescate ciertos hechos "anecdóticos" locales cuando se emitió el programa -gente que cree que "se acaba el mundo", que algunos corren a los confesionarios de las iglesias en ese momento cerradas, que otros queman el dinero guardado debajo de los colchones, etc. (L. Páez, 1982, p. 14 y sigs.)-.

Por el contrario:

- Procura ser sincera en la narración donde la mímesis -como estrategia para exponer las cosas como son o como fueron (Aristóteles, 2003, p. 115)permite al autor imbricarse con el personaje Páez;

- Relata los hechos contextualizándolos: por ejemplo, se alude a que se celebraba el Día del Ejército Ecuatoriano (L. Páez, 1982, pp. 30-31) y la memoria a la invasión peruana que parecía coincidir con la invasión marciana (p. 30);

- Habría una "dimensión moralizadora" y "una situación social problemática" (Beverley, 1987, p. 11), esto es: si bien se anunció del programa, los quiteños no prestaron la debida atención, además de que ciertas autoridades estaban de fiesta.

De ser así, ¿no hay acaso insinuaciones sobre el hábito de beber licor como determinantes para que haya ocurrido una percepción confusa de los hechos? $\mathrm{Al}$ respecto, existen varias citas en el libro sobre personajes que toman un "traguito" para el frío, o que se hallan dormidos por efecto de la embriaguez. En el discurso literario de la novela prevalece la idea de que en esa noche del 12 de febrero de 1949 una parte de la población quiteña sí estaba entre sueños y tragos, acaso un sábado festivo ligado al placer de los alcoholes. Tras cuatro meses de estar escondido Páez, luego de los hechos de ese día y tomar conciencia de que él no tenía la culpa, se presenta ante la policía y luego es juzgado. El fiscal le inquiere: “-Como quiteño que es Ud., entiendo, conoce bien a los quiteños. Quiero decir que conoce a su pueblo. Está enterado de sus costumbres, etcétera, etcétera, ¿verdad?” (L. Páez, 1982, p. 96). La repetición de la voz "etcétera" deja al lector a que se haga el juicio justo, concatenando hechos con comportamientos problemáticos ilustrados en la novela, sobre todo los 
relacionados a la dipsomanía local. Este último rasgo del discurso que lleva a que se ponga atención a un problema de lo social es quizá lo más sugestivo en Los que siembran el viento. Ahí está el aspecto de la catarsis que, por otro lado, permea a toda la novela. Pese su tono por momentos entretenido, a veces reflexivo, el espíritu de lo moralizador y la preocupación por lo social, que alegan que la transmisión radial no fue tomada como lo que debió ser, implica lo catártico. Y esto es lo que define a la tragedia clásica. Puesto que a Páez le interesaba demostrar que la transmisión radial de La Guerra de los Mundos era una ficción, hecho que se desvirtuó por las "costumbres" quiteñas -aunque también sabía que semejante transmisión había logrado desconcierto y hasta una alarmante situación en Estados Unidos en 1939 (Cantril, 2005; L. Páez, 1982, p. 99)-, el otro sentido con el que se puede tomar a la novela es con relación al de su tono trágico. Por algo su autor representa a un Páez pobre, solitario, que habla como "loco", dedicado a su oficio, consciente que había provocado un acontecimiento en el que hubo muertos, y que reconoce ante el fiscal que la transmisión fue "artísticamente imprudente", cuando aquel le pregunta si fue "una tremenda imprudencia artística el programa de los marcianos” (L. Páez, 1982, p. 98). La idea de acercarse a la tragedia está en que se debe representar a los mejores (Aristóteles, 2003, p. 34), aunque estos tengan un camino que se complica. Páez intenta alzarse como un personaje trágico.

Cuando Páez está siendo interrogado por el fiscal, leemos:

-Bien, estamos avanzando. Veamos: Ud. interpretó el papel del periodista que, ficticiamente, murió en Cotocollao. Su actuación fue patética.

- Procuré ser patético. De otra manera hubiera sido víctima de críticas severas (L. Páez, 1982, p. 98).

Adviértase que el fiscal califica de "patética" la actuación de Páez. Y este lo reafirma dando un sentido adicional al reproche, señalando que quería ser, en efecto, patético. En el contexto del teatro, Aristóteles señala que habría el lance patético o lo patético en la tragedia cuando hay escenas de muerte o de violencia (2003, pp. 64-65), el cual lleva a la peripecia y al reconocimiento, siendo el primero, "el cambio en suerte contraria" (p. 63), y el segundo, "el cambio de ignorancia en conocimiento" (p. 63). En el interior del drama, el personaje debe sufrir lo que llevará a la reflexión y al cambio de sentido de su vida. En la representación radial de La Guerra de los Mundos esto queda truncado, pero en el argumento de la novela Los que siembran el viento que narra acerca sobre el problema suscitado socialmente gracias a dicha transmisión, el personaje Páez sabe que su suerte cambia y él mismo toma conciencia de su rol en los hechos, enfrentando la justicia. La alusión del fiscal al tono de la actuación de Páez puede interpretarse metafóricamente ya sea como: "turbador", "dramático", aunque también en sentido despectivo como: "grotesco”; el significado de Páez acusado 
más bien es que quería "conmover". Habría un doble sentido en la afirmación: conmover o ser trágico.

He aquí la cuestión de la catarsis no tanto en la transmisión radial, sino en la propia novela Los que siembran el viento. Así, Aristóteles define:

la tragedia [es] una imitación de acción digna y completa, de amplitud adecuada, con lenguaje que deleita por su suavidad, usándose en las diferentes partes de ella separadamente de una de las distintas maneras de hacer suave el lenguaje; imitación que se efectúa por medio de personajes en acción y no narrativamente, logrando por medio de la piedad y el terror la expurgación de tales pasiones (2003, p. 45).

Entonces, además de trágico, la novela representa a Páez como un personaje patético tras las peripecias en las que se subsume e inspiran en nuestro caso, como lectores, la piedad o la compasión. Páez el autor se esmera en demostrar que Páez el personaje siempre ha sido inocente de los hechos de la noche del 12 de febrero de 1949, con una moralidad recta que le obliga a entregarse a la justicia con la intención de que se pruebe su inocencia -curiosamente no se dice nada en el mismo tono del otro libretista, Vergara Morales-.

En el discurso literario se reconoce a Páez como individuo moral, que quiere redimirse, y por ese efecto, los lectores deben realizar la catarsis (kátharsis), es decir, su expurgación o purificación, si atendemos además lo que dice Sánchez Palencia respecto a la tragedia y la catarsis: "imitación de una acción completa y entera que suscita temor y compasión mediante los que opera en el [lector] la catarsis del tipo de afecciones que sufren los personajes trágicos” (1996, p. 144). Sabemos que Páez, el hombre de radioteatro, sí fue absuelto (Cuesta y Cuesta, 1982), y que también ganó el premio de teatro de 1955, hechos que, relatados en la novela, despiertan comentarios envidiosos o maliciosos. Es por ello que el autor cuenta, que, para cerrar la tragedia del personaje Páez y su destino, "sin volver la cabeza para nada, confundido en el tronar de los motores del avión, el hombre se larga de una vez" (L. Páez, 1982, p. 108). Así, se nos hace pensar que la tierra sembrada de guijarros, tal como declaró al recibir el premio (cit. en M. de Uzcátegui, 1955, p. 156), es en realidad un Quito resentido, una ciudad que le perdonó lo que pudo ser solo un programa de entretenimiento.

\section{Conclusión}

La Guerra de los Mundos versión ecuatoriana, al igual que la original norteamericana, hurgó el miedo y suscitó el pánico. La diferencia con la obra radial de Welles es que la versión de Páez-Vergara duró apenas 21 minutos, en tanto la primera sí llegó a los 60 pese al desconcierto y a los problemas sociales en distintas ciudades de Estados Unidos.

El centro del problema fue Quito, ciudad donde está el poder gubernamental, pero además es imaginada como ciudad conventual, es decir, urbe que 
tempranamente deja sus calles solitarias considerando la supuesta mojigatería social. Yendo más allá de los estudios de psicología social o los de comunicación relativos al influjo de los medios de comunicación, hay que afirmar que la novela de Páez pone de manifiesto lo siguiente:

- Un ambiente citadino en el que prevalecía un estado de adormecimiento por el consumo de alcoholes, replicado por el contexto festivo que se vivía;

- La poca atención que prestó la ciudadanía o la opinión pública los anuncios previos que se habían hecho relativos a la emisión del radioteatro;

- Que la audiencia no supo diferenciar entre la ficción radial y la realidad de la supuesta invasión;

- La memoria aún no olvidada de la invasión peruana -y quizá el peso de la realidad de la Segunda Guerra Mundial que además terminaría con la detonación de la bomba atómica-;

- El rol de los libretistas, sobre todo Páez, en la elaboración de un producto cultural novedoso que pretendía motivar la atención de la audiencia al teatro radial.

La consecuencia, con todo, fue la constitución de un acontecimiento que tuvo muertos y heridos, adversidades en el interior de las familias, pedidos de divorcio o de casamiento -ya que los quiteños pensaron que era el fin del mundo-. Lo apocalíptico permeó de sentido a la misma memoria de alguna invasión histórica. Aunque se crea que lo apocalíptico puede ser la clausura de toda existencia, Páez juega en su novela a mostrarla como un dispositivo para reflexionar no solo sobre lo social, sino también sobre su propia condición como escritor y creativo. Kumar manifiesta que el escritor de historias apocalípticas a la par que evidencian los signos de los tiempos -para el caso ecuatoriano, una memoria social y política aún no resuelta-, también muestran los de la esperanza (2000, p. 236): Páez con su obra radial puso de manifiesto conflictos sociales que parecen ser obvios, pero a la vez develó al hombre, al creativo como ejemplo de un ethos: como todo ciudadano que siente que es honesto y cabal, desafía a que se le reconozca como tal, poniendo en entredicho la actitud o comportamiento de una sociedad frente a los productos culturales.

\section{Referencias bibliográficas}

Agamben, G. (2000). Lo que queda de Auschwitz: El archivo y el testigo. Homo Sacer III (A. Gimeno Cuspinera, Trad.). Valencia: Pre-Textos.

Álamo Felices, F. (2011). Los subgéneros novelescos (Teoría y modalidades narrativas). Almería: Universidad Almería.

Alemán, G. (2014). La muerte silba un blues. Bogotá: Random House.

Aristóteles. (2003). Poética (E. Schlesinger \& J. M. de Estrada, Trads.). Buenos Aires: Losada.

Bachelard, G. (2016). La poética del espacio (15a.; E. De Champourcín, Trad.). Buenos Aires: Fondo de Cultura Económica. 
Beck, P. J. (2016). The War of the Worlds: From H.G. Wells to Orson Welles, Jeff Wayne, Steven Spielberg and Beyond. London: Bloomsbury Publishing.

Bergson, H. (2006). Materia y memoria: Ensayo sobre la relación de cuerpo con el espíritu (P. Ires, Trad.). Buenos Aires: Cactus.

Beverley, J. (1987). Anatomía del testimonio. Revista de Crítica Literaria Latinoamericana, 13(25), 7-16. https://doi.org/10.2307/4530303

Cantril, H. (2005). La psicología del pánico. En J. Jiménez Heffernan (Trad.), El guión radiofónico de La invasión desde Marte sobre la novela La guerra de los mundos de H.G. Wells (pp. 107-250; De O. Welles). Madrid: Abada.

Corral Burbano de Lara, F., Albornoz Guarderas, V., Pachano Holguín, S., Pérez Ordóñez, D., Serrano Pérez, V., \& Zapater, I. I. (2006). Testigo del siglo: El Ecuador visto a través de diario El Comercio, 1906-2006. Quito: El Comercio.

Correa B., F. (2014, diciembre 28). "Reina y Señora”: Pasacalle himno popular de los imbabureños. Revista Memorias Porteñas y crónicas de El Expreso, 74, 13.

Cuesta y Cuesta, A. (1982). [Contratapa] Los que siembran el viento. En L. Páez, Los que siembran el viento (p. [Contratapa]). Caracas: Arte.

De la Torre, A. (2006). Gonzalo Benítez: Tras una cortina de años. Quito: Fondo de Salvamento del Patrimonio Cultural de Quito.

Deleuze, G. (2005). Lógica del sentido (M. Morey \& V. Molina, Trads.). Barcelona: Paidós.

Égüez, I. (1975). La Linares. Quito: Pontificia Universidad Católica del Ecuador.

Fernández, J. (1956). Tránsito a la libertad: Biografía del diario "El Comercio". Quito: El Comercio.

Foucault, M. (2013). ¿̇Qué es usted, profesor Foucault? Sobre la arqueología y su método (E. Castro, Ed.; H. Pons, Trad.). Buenos Aires: Siglo XXI.

Gómez, J. L. (1996). Historia de una histeria. Chasqui. Revista Latinoamericana de Comunicación, (54), 91-92. Recuperado de http://repositorio.flacsoandes.edu.ec/handle/10469/13047

González Echevarría, R. (2011). Mito y archivo: Una teoría de la narrativa latinoamericana (2a.). Ciudad de México: Fondo de Cultura Económica.

Guerra Gándara, M. (2008). Testimonios del radioteatro en Quito. Quito: El Conejo y Fondo de Salvamento del Patrimonio Cultural de Quito.

Ibarra, H., \& Novillo, V. (2010). La radio en Quito, 1935-1960. Quito: Museo de la Ciudad.

Kumar, K. (2000). El apocalipsis, el milenio y la utopía en la actualidad. En M. A. Neira Bigorra (Trad.), La teoría del apocalipsis y los fines del mundo (pp. 233-260). México: Fondo de Cultura Económica.

Larrea V., C. (2002). Yo estuve en La Guerra de los Mundos. En E. Freire Rubio (Ed.), Quito: Testimonio y Nostalgia: Vol. I (pp. 286-294). Quito: Libresa.

Orquera Polanco, K. (2020). La representación de la Guerra de 1941 en diario El Comercio. Textos y Contextos, 1(21), 63-74. https://doi.org/10.29166/tyc.v1i21.2476

Páez, L. (1982). Los que siembran el viento. Caracas: Arte.

Páez, X. (2010, agosto). Las canciones del compositor Leonardo Páez: Recopilación hecha en Ecuador y Venezuela. El diablo ocioso (EDO): revista musical ecuatoriana, 7, 90-166. Recuperado de https://issuu.com/memoriamusical/docs/revistamusicaledo7

Pareja Diezcanseco, A. (1979). Ecuador: La República de 1830 a nuestros días (6a.). Quito: Universitaria.

Pavel, T. G. (1995). Mundos de ficción (J. Fombona, Trad.). Caracas: Monte Ávila Editores. Ribadeneira, J. (2006). El Comercio: 100 años de historia y testimonios. Quito: El Comercio. 
Rodrigo-Mendizábal, I. (2014, septiembre). Lo fantástico de los marcianos en Quito. Rocinante, (71), 16-23. Recuperado de https://cienciaficcionecuador.wordpress.com/2014/og/10/ lo-fantastico-de-los-marcianos-en-quito/

Rodrigo-Mendizábal, I. (2015, febrero 15). El libreto (ficticio) de la invasión marciana a Quito. Revista Cartón Piedra - El Telégrafo, (174), 6-9. Recuperado de https://www.eltelegrafo. com.ec/noticias/carton/1/el-libreto-ficticio-de-la-invasion-marciana-a-quito

Rodrigo-Mendizábal, I. (2021, febrero 13). La invasión marciana en Quito-Ecuador [Revista digital]. Recuperado de Amazing Stories website: https://amazingstories.com/2021/o2/ la-invasion-marciana-en-quito-ecuador/

San Félix, Á. (1991). Radiodifusión en la mitad del mundo: Apuntes históricos. Quito: Editora Nacional.

Sánchez Palencia, Á. (1996). Catarsis en la poética de Aristóteles. Anales del Seminario de Historia de la Filosofía, 13, 127-147. Recuperado de https://revistas.ucm.es/index.php/ ASHF/article/view/ASHF9696120127A

Schwartz, A. B. (2015). Broadcast Hysteria: Orson Welles's War of the Worlds and the Art of Fake News. New York: Hill and Wang, div. of Farrar, Strauss and Giroux.

Uzcátegui, M. de. (1955, marzo). Movimiento cultural y pedagógico en el país: Premiación de obras teatrales. Revista Ecuatoriana de Educación, 36, 154-156. Recuperado de http:// repositorio.casadelacultura.gob.ec/bitstream/3400o/18751/2/CCE-REE-V8-N36-1955.pdf

Uzcátegui, E. (1985, octubre). Ciencia ficción o ciencia espectáculo: ¿Tienen valor didáctico? Boletín de Informaciones Científicas Nacionales, 118, 7-11. Recuperado de http:// repositorio.casadelacultura.gob.ec/bitstream/3400o/18977/2/CCE-BICN-N118-1985.pdf

Vacas G., H. (1975). No es un prólogo. En Leonado Páez, Romancero quiteño (2a., pp. 5-12). Caracas: Arte.

Welles, O. (2005). El guion radiofónico de La invasión desde Marte sobre la novela La guerra de los mundos de H.G. Wells (J. Jiménez Heffernan, Trad.). Madrid: Abada.

Wells, H. G. (1898). The War of the Worlds. London: Harper \& Brothers Publishers.

Wyss, J. (2014, febrero 22). In Ecuador, after the green men from Mars invaded, the real tragedy began. Miami Herald. Recuperado de https://www.miamiherald.com/news/ nation-world/world/americas/article1960647.html 